\title{
Effect of electrode contact location on clinical efficacy of pallidal deep brain stimulation in primary generalised dystonia
}

\author{
S Tisch, L Zrinzo, P Limousin, K P Bhatia, N Quinn, K Ashkan, M Hariz
}

J Neurol Neurosurg Psychiatry 2007;78:1314-1319. doi: 10.1136/jnnp.2006.109694

See end of article for authors' affiliations

Correspondence to: Dr S Tisch, Unit of Functiona Neurosurgery, Sobell Department, Institute of Neurology, University College London, Box 146, 8-11 Queen Square, London WCIN 3BG, UK;

s.tisch@ion.ucl.ac.uk

Received 24 October 2006 Revised 12 March 2007 Accepted 15 March 2007 Published Online First 18 April 2007

(.....................
Objectives: To determine the effect of electrode contact location on efficacy of bilateral globus pallidus internus (GPi) deep brain stimulation (DBS) for primary generalised dystonia (PGD).

Subjects and methods: A consecutive series of 15 patients with PGD ( 10 females, mean age 42 years, seven DYT1) who underwent bilateral GPi DBS, were assessed using the Burke-Fahn-Marsden (BFM) dystonia scale before and 6 months after surgery. The position of the stimulated electrode contact(s) was determined from the postoperative stereotactic MRI. Contralateral limb and total axial BFM subscores were compared with the location of the stimulated contact(s) within the GPi.

Results: The mean total BFM score decreased from 38.9 preoperatively to 11.9 at 6 months, an improvement of $69.5 \%(p<0.00001)$. Cluster analysis of the stimulated contact coordinates identified two groups, distributed along an anterodorsal to posteroventral axis. Clinical improvement was greater for posteroventral than anterodorsal stimulation for the arm $(86 \%$ vs $52 \% ; p<0.05)$ and trunk $(96 \%$ vs $65 \% ; p<0.05)$ and inversely correlated with the $y$ coordinate. For the leg, posteroventral and anterodorsal stimulation were of equivalent efficacy. Overall clinical improvement was maximal with posteroventral stimulation (89\% vs $67 \%$; $p<0.05)$ and inversely correlated with the $y(A-P)$ coordinate $(r=-0.62, p<0.05)$.

Conclusion: GPi DBS is effective for PGD but outcome is dependent on contact location. Posteroventral GPi stimulation provides the best overall effect and is superior for the arm and trunk. These results may be explained by the functional anatomy of GPi and its outflow tracts.
$\mathrm{P}$ rimary generalised dystonia (PGD) is a movement disorder characterised by involuntary muscle contractions causing abnormal postures and spasms. ${ }^{1}$ The failure of medical treatment has led to renewed interest in functional neurosurgical approaches to its treatment. Earlier positive reports of ablative pallidal surgery in dystonia $^{2}$ and the subsequent observations of improvement of dystonia in Parkinson's disease (PD) with posteroventral pallidotomy and DBS led to the first attempts to treat dystonia using globus pallidus internus (GPi) deep brain stimulation (DBS) by Coubes et al in 1996. ${ }^{3}$ Since then, GPi DBS has emerged as an effective treatment for PGD. ${ }^{4}$ Despite this progress and the more widespread acceptance of the technique, there is still debate about the optimal target within the GPi to achieve the best effect in dystonia. Most surgeons target the posteroventral portion of the GPi, the classical target for pallidotomy developed by Leksell and Laitinen. ${ }^{6}$ However, to date there have been few data to support the superiority of this target in dystonia, or whether within this region there may be an optimal zone to achieve the best effect.

We sought to explore the relationship between the precise location of the therapeutically stimulated electrode contact and the magnitude of clinical benefit in a consecutive series of patients with PGD who all underwent bilateral GPi DBS. We were interested to determine if within the GPi there is any regional stratification of the efficacy of stimulation for dystonia.

\section{METHODS \\ Subjects}

We studied a consecutive series of 15 patients with PGD. The clinical characteristics of the patients are summarised in table 1 . Patient No 5 had a previous thalamotomy 23 years previously. The study was approved by the Joint Research Committee of the National Hospital for Neurology and Neurosurgery and the Institute of Neurology, London, UK.

\section{Surgical procedures and stimulation parameters}

All patients underwent bilateral implantation of electrodes into the GPi and chronic stimulation. The quadripolar DBS electrode model 3389, with four platinum-iridium cylindrical surfaces ( $1.27 \mathrm{~mm}$ diameter, $1.5 \mathrm{~mm}$ in length and $2 \mathrm{~mm}$ centre-tocentre separation) and Kinetra model 7428 implanted pulse generator (Medtronic Neurological Division, Minneapolis, Minnesota, USA) were used in all except four patients where model 3387 ( $3 \mathrm{~mm}$ centre-to-centre separation) electrodes were used. Surgery was performed under general anaesthesia using the Leksell G frame (Elekta Instruments, Sweden) with direct targeting of the posteroventral $\mathrm{GPi}$, as visualised on proton density sequence ${ }^{7}$ stereotactic MRI, $1.5 \mathrm{~T}, 2 \mathrm{~mm}$ contiguous slices. The entrance point into the skull was made $2-2.5 \mathrm{~cm}$ lateral to the midline at the level of the coronal suture, which provides an orthogonal approach. The ring angle (anteroposterior angle) was between 70 and $80^{\circ}$, and the arc angle $85-95^{\circ}$. Intraoperative impedance recording was used to delineate grey and white matter boundaries; microelectrode recording was not used. Confirmation of electrode placement in the GPi was obtained in all patients with immediate post-implantation stereotactic MRI. All patients received monopolar stimulation with one or two adjacent active contacts. Stimulation parameters were individualised in each patient and chosen for the best clinical effect and the least side effects. Eight patients were stimulated at ventral contacts; in seven patients (12 sides) the

Abbreviations: BFM, Burke-Fahn-Marsden; DBS, deep brain stimulation; Gpe, globus pallidus externus; Gpi, globus pallidus internus; PD, Parkinson's disease; PGD, primary generalised dystonia 
Table 1 Patient characteristics

\begin{tabular}{|c|c|c|c|c|c|c|c|c|c|}
\hline $\begin{array}{l}\text { Patient } \\
\text { No }\end{array}$ & Sex & $\begin{array}{l}\text { Age } \\
\text { (y) }\end{array}$ & $\begin{array}{l}\text { Disease } \\
\text { duration } \\
\text { (y) }\end{array}$ & $\begin{array}{l}\text { DYT1 } \\
\text { gene } \\
\text { status }\end{array}$ & $\begin{array}{l}\text { Site of } \\
\text { onset }\end{array}$ & $\begin{array}{l}\text { Worst } \\
\text { affected } \\
\text { areas }\end{array}$ & $\begin{array}{l}\text { BFM score } \\
\text { pre-op/6 mo } \\
(0-120)\end{array}$ & Medications & DBS parameters \\
\hline 1 & $\mathrm{~F}$ & 18 & 9 & + & $\mathrm{R}$ hand & $\begin{array}{l}\text { Trunk, } \\
\text { R limbs }\end{array}$ & $48 / 1$ & Trihexyphenidyl & $\begin{array}{l}\text { R: } 4,5-, 3.9 v, 60 \mu \mathrm{s}, \\
130 \mathrm{~Hz} \\
\text { L: } 0,1-, 3.9 v, 60 \mu \mathrm{s}, \\
130 \mathrm{~Hz}\end{array}$ \\
\hline 2 & M & 24 & 16 & - & $\mathrm{R}$ hand & $\begin{array}{l}\text { Neck, trunk, } \\
\text { R limbs }\end{array}$ & $73 / 15$ & Clonazepam & $\begin{array}{l}\text { R: } 4,5-, 3.9 v, 90 \mu \mathrm{s}, \\
130 \mathrm{~Hz} \\
\text { L: } 0,1-, 3.8 v, 90 \mu \mathrm{s}, \\
130 \mathrm{~Hz}\end{array}$ \\
\hline 3 & M & 47 & 37 & + & L leg & $\begin{array}{l}\text { Neck, trunk, } \\
\text { L side }\end{array}$ & $52 / 22$ & $\begin{array}{l}\text { Diazepam, } \\
\text { Tetrabenazine }\end{array}$ & $\begin{array}{l}\text { R: } 4-, 3.5 v, 90 \mu \mathrm{s}, \\
130 \mathrm{~Hz} \\
\text { L: } 0,1-, 3.3 v, 60 \mu \mathrm{s}, \\
130 \mathrm{~Hz}\end{array}$ \\
\hline 4 & $\mathrm{~F}$ & 23 & 12 & - & $R$ leg & $\begin{array}{l}\text { Trunk, } \\
\text { R leg }\end{array}$ & $53 / 32$ & None & $\begin{array}{l}\text { R: } 5-, 4.0 v, 60 \mu \mathrm{s}, \\
130 \mathrm{~Hz} \\
\text { L: } 1-, 4.2 v, 60 \mu \mathrm{s}, \\
130 \mathrm{~Hz}\end{array}$ \\
\hline 5 & $\mathrm{~F}$ & 52 & 36 & + & L arm & L limbs & $29 / 7$ & None & $\begin{array}{l}\text { R: } 4-, 3.0 v, 60 \mu \mathrm{s}, \\
130 \mathrm{~Hz} \\
\mathrm{~L}: 0-, 3.0 \mathrm{v}, 60 \mu \mathrm{s}, \\
130 \mathrm{~Hz}\end{array}$ \\
\hline 6 & $\mathrm{~F}$ & 16 & 7 & + & $R$ leg & $\begin{array}{l}\mathrm{R} \text { limbs, } \\
\text { trunk }\end{array}$ & $20 / 1$ & $\begin{array}{l}\text { L-dopa, } \\
\text { Trihexyphenidyl }\end{array}$ & $\begin{array}{l}\text { R: } 4-, 2.9 v, 60 \mu \mathrm{s}, \\
130 \mathrm{~Hz} \\
\mathrm{~L}: 0-, 2.9 \mathrm{v}, 60 \mu \mathrm{s}, \\
130 \mathrm{~Hz}\end{array}$ \\
\hline 7 & $\mathrm{~F}$ & 63 & 4 & - & Trunk & $\begin{array}{l}\text { Trunk, } \\
\text { both legs }\end{array}$ & $23 / 3$ & $\begin{array}{l}\text { L-dopa, } \\
\text { Trihexyphenidyl }\end{array}$ & $\begin{array}{l}\text { R: } 6-, 4.6 v, 90 \mu \mathrm{s}, \\
130 \mathrm{~Hz} \\
\mathrm{~L}: 2-, 4.6 \mathrm{v}, 90 \mu \mathrm{s}, \\
130 \mathrm{~Hz}\end{array}$ \\
\hline 8 & $\mathrm{~F}$ & 54 & 43 & - & $\mathrm{R}$ hand & L limbs & $24 / 9$ & None & $\begin{array}{l}\text { R: } 4-, 3.7 v, 60 \mu \mathrm{s}, \\
130 \mathrm{~Hz} \\
\mathrm{~L}: 1-, 3.7 \mathrm{v}, 60 \mu \mathrm{s}, \\
130 \mathrm{~Hz}\end{array}$ \\
\hline 9 & $\mathrm{~F}$ & 36 & 25 & + & L foot & $\begin{array}{l}\text { Trunk, } \\
\text { L limbs }\end{array}$ & $21 / 1$ & Trihexyphenidyl & $\begin{array}{l}\text { R: } 4-, 4.6 v, 90 \mu \mathrm{s}, \\
130 \mathrm{~Hz} \\
\text { L: } 0-, 4.2 v, 90 \mu \mathrm{s}, \\
130 \mathrm{~Hz}\end{array}$ \\
\hline 10 & M & 62 & 43 & - & Neck & $\begin{array}{l}\text { Neck, trunk, } \\
\text { L arm }\end{array}$ & $28 / 15$ & $\begin{array}{l}\text { Trihexyphenidyl, } \\
\text { Baclofen, } \\
\text { Clonazepam }\end{array}$ & $\begin{array}{l}\text { R: } 6-, 3.7 v, 90 \mu \mathrm{s}, \\
130 \mathrm{~Hz} \\
\mathrm{~L}: 1-, 3.7 \mathrm{v}, 90 \mu \mathrm{s}, \\
130 \mathrm{~Hz}\end{array}$ \\
\hline 11 & $\mathrm{~F}$ & 22 & 15 & + & L foot & $\begin{array}{l}\text { Trunk, } \\
\text { both legs }\end{array}$ & $51 / 11$ & $\begin{array}{l}\text { Trihexyphenidyl, } \\
\text { Baclofen }\end{array}$ & $\begin{array}{l}\text { R: } 4-, 3.6 v, 60 \mu \mathrm{s}, \\
130 \mathrm{~Hz} \\
\mathrm{~L}: 0-, 3.6 \mathrm{v}, 60 \mu \mathrm{s}, \\
130 \mathrm{~Hz}\end{array}$ \\
\hline 12 & $\mathrm{~F}$ & 64 & 50 & - & $\mathrm{R}$ hand & $\begin{array}{l}\text { Trunk, } \\
\text { R limbs }\end{array}$ & $46 / 13$ & None & $\begin{array}{l}\text { R: } 5,6-, 3.5 \mathrm{v}, 60 \mu \mathrm{s} \text {, } \\
130 \mathrm{~Hz} \\
\mathrm{~L}: 1,2-, 3.5 \mathrm{v}, 60 \mu \mathrm{s}, \\
130 \mathrm{~Hz}\end{array}$ \\
\hline 13 & M & 62 & 7 & - & L leg & $\begin{array}{l}\text { Neck, L leg, } \\
\text { R arm }\end{array}$ & $64 / 30$ & None & $\begin{array}{l}\text { R: } 4,5-, 3.5 v, 60 \mu \mathrm{s}, \\
130 \mathrm{~Hz} \\
\text { L: } 1,2-, 3.5 \mathrm{v}, 60 \mu \mathrm{s}, \\
130 \mathrm{~Hz}\end{array}$ \\
\hline 14 & M & 47 & 26 & - & Neck & $\begin{array}{l}\text { Neck, } \\
\text { R arm }\end{array}$ & $25 / 12$ & None & $\begin{array}{l}\text { R: } 4,5-, 3.5 v, 90 \mu \mathrm{s}, \\
130 \mathrm{~Hz} \\
\text { L: } 0,1-, 3.5 \mathrm{v}, 90 \mu \mathrm{s}, \\
130 \mathrm{~Hz}\end{array}$ \\
\hline 15 & $\mathrm{~F}$ & 42 & 30 & + & $R$ foot & R arm, leg & $27 / 6$ & None & $\begin{array}{l}\text { R: } 5-, 3.5 v, 60 \mu \mathrm{s}, \\
130 \mathrm{~Hz} \\
\text { L: } 1-, 3.5 \mathrm{v}, 60 \mu \mathrm{s}, \\
130 \mathrm{~Hz}\end{array}$ \\
\hline
\end{tabular}

BFM, Burke-Fahn-Marsden; DBS, deep brain stimulation.

most ventral contacts ( 0 and 4 ) were not used for chronic stimulation. The reasons for not using the most ventral contacts were capsular (corticospinal) response with tension in the contralateral face or arm, or dysarthria (patient Nos 8, 10, 15), dizziness (patient No 4), better clinical effect of more dorsal contacts (patient No 7) and not tried for chronic stimulation from the outset (patient Nos 12 and 13). The stimulation parameters in each patient at 6 months are shown in table 1 .

\section{Clinical assessment}

Clinical assessment was performed using the Burke-FahnMarsden scale (BFM), which is a validated clinical measure in generalised dystonia. ${ }^{8}$ Patients were assessed preoperatively and 6 months after surgery. Right and left hemibody scores were derived from the BFM movement scores for the arm and leg. The BFM movement scores for axial items (eyes, mouth, speech, neck, trunk), which are unpaired data, were analysed separately on a whole patient basis rather than by sides. 
Total scores
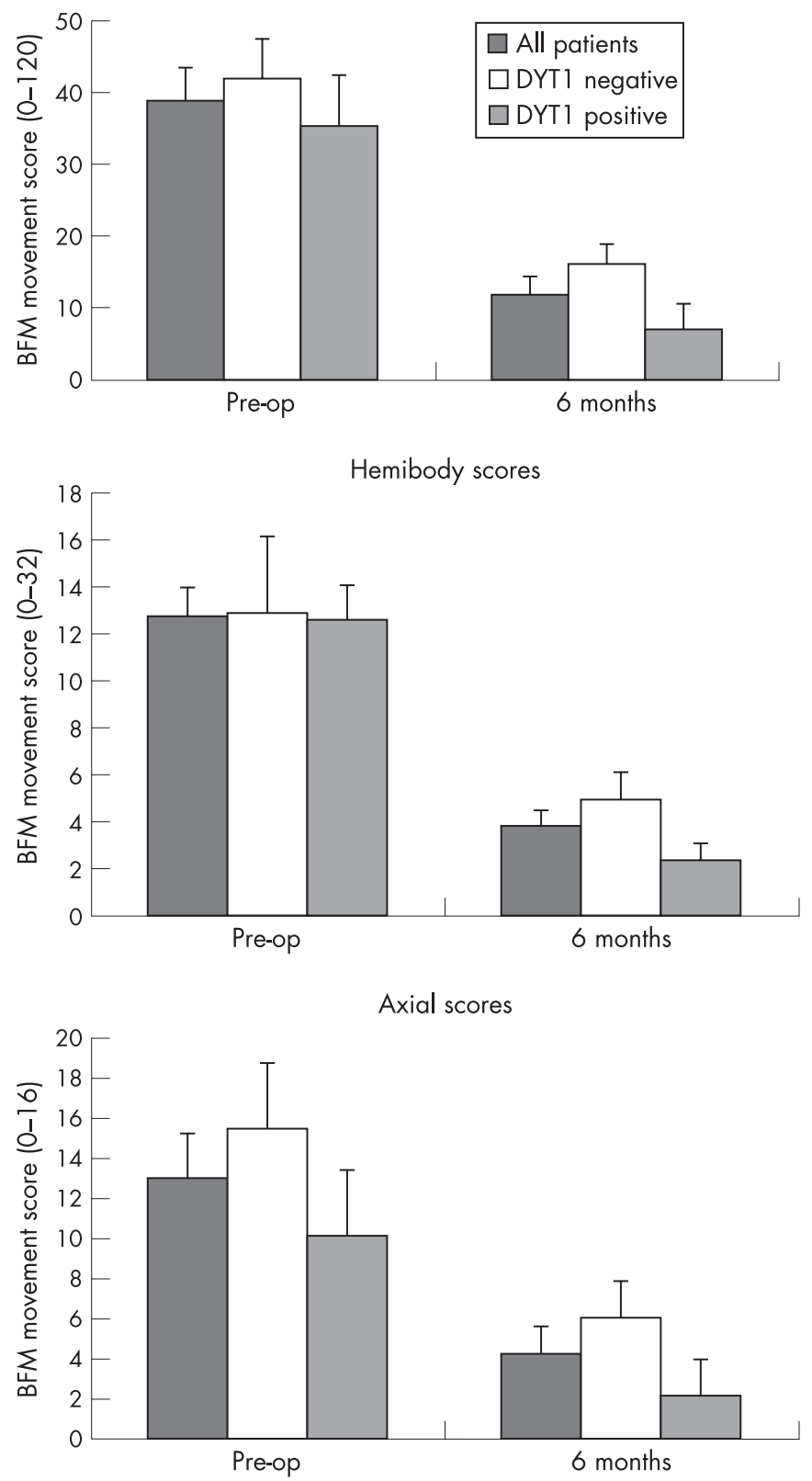

Figure 1 Mean Burke-Fahn-Marsden (BFM) movement scores for the whole body, hemibody (arm, leg) and axial (eyes, mouth, speech/swallow, neck and trunk), before and 6 months after bilateral globus pallidus internus deep brain stimulation. Values are mean (SEM). All decreases in BFM were significant at the $p<0.05$ level.

\section{MRI analysis and determination of electrode contact position}

MRI images were analysed using the Stealth workstation (Framelink TM; Medtronic). The investigator determining contact location (LZ) was blinded to the clinical scores of the patients. Electrode contacts were identified on the postoperative stereotactic MRI. The centre of the electrode contact was determined as the centre of its artefact visible on the MRI image. Electrode contact position with respect to mid-commissural point, atlas defined target and the visible anatomical target was determined. The visible target was spatially normalised to atlas target of $x=21 \mathrm{~mm}, y=2 \mathrm{~mm}, z=-5 \mathrm{~mm}$ in relation to the mid-commissural point. The Cartesian coordinates of the active contact after this transposition were then derived. This transposition normalised for anatomical variation between and within patients. Where two adjacent contacts were stimulated (11 sides), the geometric mean of the two stimulated contacts was used. In addition to quantitative localisation of the stimulated electrode contacts, we also determined their position in relation to anatomical boundaries of the GPi visible on MRI images. Using the same MRI analysis methods, we also determined the targeting error for each electrode as the distance between the intended target and the electrode position.

\section{Statistical analysis}

Clinical and contact location data were cross tabulated so that total hemibody, arm and leg scores were paired with the coordinates of the contralateral active electrode contact (30 sides). Total scores and axial subscores were paired with the mean $\mathrm{x}, \mathrm{y}$ and $\mathrm{z}$ coordinates of the active contacts of both electrodes ( 15 patients), to enable the data to be treated on a whole patient basis rather than by sides. Cluster analysis ( $\mathrm{K}$ means cluster) was used to identify subgroups of electrode contacts within geographically distinct domains. Differences between groups were determined using $\chi^{2}$ and two tailed unpaired $\mathrm{t}$ tests. Repeated measures ANOVA was used to explore the effects of coordinate and DYTl status on clinical outcome. Correlations were performed using the Pearson correlation coefficient. A p value $<0.05$ was considered significant. All statistics were performed using SPSS for Windows v 11.5.

\section{RESULTS}

\section{Clinical outcome}

Dystonia improved in all patients after surgery. The mean BFM movement score decreased from 38.9 preoperatively to 11.9 at 6 months, an improvement of $69.5 \%(\mathrm{p}<0.00001)$. The BFM disability score improved from 9.0 to 4.1 , a $58 \%$ improvement $(\mathrm{p}<0.00001)$. The mean percentage improvement in hemibody scores was $67.8 \% \quad(\mathrm{p}<0.0001)$. There was no significant difference in outcome between arm and leg $(63.8 \%$ vs $72.9 \%$; NS) or right and left body sides ( $67.5 \%$ vs $68.0 \%$; NS). Patients with DYTl showed significantly greater improvement in total movement score $(82.5 \%$ vs $61.5 \%$; $<<0.05)$, hemibody score ( $81.8 \%$ vs $55.4 \%$; $<<0.01$ ) but not axial $(89.4 \%$ vs $63.9 \%$; NS) or disability score (69.5\% vs $50.9 \%$; NS). Improvement in hemibody score was non-significantly greater for 3387 than 3389 electrodes $(79.0 \%$ vs $63.6 \%$; NS). The clinical outcome results are summarised in fig 1 . We observed in two patients (patient Nos 5 and 8) the development of delayed onset akinesia with gait slowing, and difficulty arising from sitting and turning in bed. In both patients these akinetic features occurred with stimulation of ventral contacts and improved by changing to more dorsal contacts.

\section{Electrode contact location}

Table 2 shows the electrode contact position in relation to pallidal anatomy, for each patient side.

The MRI of patient No 1 is shown in fig 2. For the entire cohort, the mean coordinates of the stimulated contact were $x=20.8 \mathrm{~mm} \quad(18.3-22.4), \quad y=3.2 \mathrm{~mm} \quad(1.2-5.1) \quad$ and $\mathrm{z}=-0.76 \mathrm{~mm}(-5.3-2.2)$. Electrode contacts on the left brain side were more medial than on the right $(20.2 \mathrm{~mm}$ vs $21.4 \mathrm{~mm}$; $\mathrm{p}<0.001$ ), but for $\mathrm{y}$ and $\mathrm{z}$ coordinates there was no significant difference between right and left sides. The mean Euclidean targeting error for all of the electrodes was 0.9 (SD 0.5) mm and was not significantly different between right and left sides. As the targeting error was acceptably small and equal on both sides, the likely explanation of the left electrode being more medial is that the GPi is anatomically more medial on the left than on the right, as has been shown in a previous study. ${ }^{7}$ 
Table 2 Electrode contact position in relation to pallidal anatomy, for each patient side

\begin{tabular}{|c|c|c|c|c|c|c|c|c|}
\hline \multirow{2}{*}{$\begin{array}{l}\text { Patient } \\
\text { No }\end{array}$} & \multicolumn{4}{|l|}{ Left side } & \multicolumn{4}{|l|}{ Right side } \\
\hline & Contact 0 & Contact 1 & Contact 2 & Contact 3 & Contact 4 & Contact 5 & Contact 6 & Contact 7 \\
\hline 1 & $\mathrm{GPi}^{*}$ & GPi/MML* & $\mathrm{GPe}$ & GPe/LML & $\mathrm{GPi}^{*}$ & GPi/MML* & $\mathrm{GPe}$ & $\mathrm{GPe} / \mathrm{LML}$ \\
\hline 2 & $\mathrm{GPi}^{*}$ & $\mathrm{GPi}^{*}$ & $\mathrm{GPe}$ & GPe/LML & $\mathrm{GPi}^{*}$ & GPi/MML* & $\mathrm{GPe}$ & LML/PT \\
\hline 3 & $\mathrm{GPi}^{*}$ & $\mathrm{GPi}^{*}$ & GPi/MML & $\mathrm{GPe}$ & $\mathrm{GPi}^{*}$ & GPi/MML & $\mathrm{GPe}$ & $\mathrm{GPe}$ \\
\hline 4 & GPi & GPi/MML* & $M M L / G P e$ & GPe/LML & GPi & GPi/MML* & GPe & $\mathrm{GPe}$ \\
\hline 5 & $\mathrm{GPi}^{*}$ & GPi/MML & $\mathrm{GPe}$ & $\mathrm{GPe}$ & $\mathrm{GPi}^{*}$ & GPi/MML & $\mathrm{GPe}$ & $\mathrm{GPe} / \mathrm{LML}$ \\
\hline 6 & $\mathrm{GPi}^{*}$ & GPi & $\mathrm{GPi}$ & GPi & $\mathrm{GPi}^{*}$ & GPi/MML & $\mathrm{MML} / \mathrm{GPi}$ & $\mathrm{GPe}$ \\
\hline 7 & GPi & GPi & $\mathrm{GPi}^{*}$ & GPi/MML & GPi & $\mathrm{GPi}$ & $\mathrm{GPi}^{*}$ & GPi/MML \\
\hline 8 & GPi & $\mathrm{GPi}^{*}$ & GPi/MML & $\mathrm{GPe}$ & $G \mathrm{Pi}^{*}$ & GPi/MML & $\mathrm{GPe}$ & LML/PT \\
\hline 9 & $\mathrm{GPi}^{*}$ & GPi & $\mathrm{GPi}$ & GPi/MML & $\mathrm{GPi}^{*}$ & $\mathrm{MML} / \mathrm{GPe}$ & $\mathrm{GPe}$ & $\mathrm{GPe} / \mathrm{LML}$ \\
\hline 10 & GPi & GPi/MML* & $\mathrm{MML} / \mathrm{GPe}$ & $\mathrm{GPe}$ & IC/GPi & $\mathrm{GPi}$ & GPi/MML* & $M M L$ \\
\hline 11 & $\mathrm{GPi}^{*}$ & GPi/MML & MML & $\mathrm{GPe}$ & $\mathrm{GPi}^{*}$ & GPi/MML & MML & $\mathrm{MML} / \mathrm{GPe}$ \\
\hline 12 & GPi & $\mathrm{GPi} / \mathrm{MML}^{*}$ & $\mathrm{GPe}^{*}$ & GPe & GPi & $G \mathrm{Pi}^{*}$ & $\mathrm{GPi} / \mathrm{MML}^{*}$ & $\mathrm{GPe}$ \\
\hline 13 & GPi & $\mathrm{GPi}^{*}$ & $\mathrm{GPi} / \mathrm{MML}^{*}$ & LML/PT & $\mathrm{GPi}^{*}$ & GPi/MML* & $\mathrm{MML} / \mathrm{GPe}$ & $\mathrm{GPe}$ \\
\hline 14 & $\mathrm{GPi}^{*}$ & GPi/MML* & MML & $\mathrm{MML} / \mathrm{GPe}$ & $\mathrm{GPi}^{*}$ & $\mathrm{GPe}^{*}$ & $\mathrm{GPe} / \mathrm{LL}$ & LML/PT \\
\hline 15 & GPi & $\mathrm{GPi}^{*}$ & GPi/MML & GPe & GPi & GPi/MML* & GPe/LML & $\mathrm{GPe}$ \\
\hline
\end{tabular}

GPe, globus pallidus externus; GPi, globus pallidus internus; IC, internal capsule; LML, lateral medullary lamina (separates GPe and putamen); MML, medial medullary lamina (separates GPi and GPe); PT, putamen.

*Stimulated contact(s).

Cluster analysis of the stimulated contact coordinates identified two spatially distinct groups with the following geometric centres: cluster 1 ( 10 sides $) \mathrm{x}=20.8 \mathrm{~mm}$, $\mathrm{y}=2.2 \mathrm{~mm}, \mathrm{z}=-3.1 \mathrm{~mm}$ and cluster 2 (20 sides) $\mathrm{x}=20.8 \mathrm{~mm}, \mathrm{y}=3.6 \mathrm{~mm}, \mathrm{z}=0.4 \mathrm{~mm}$. Clustering was influ-
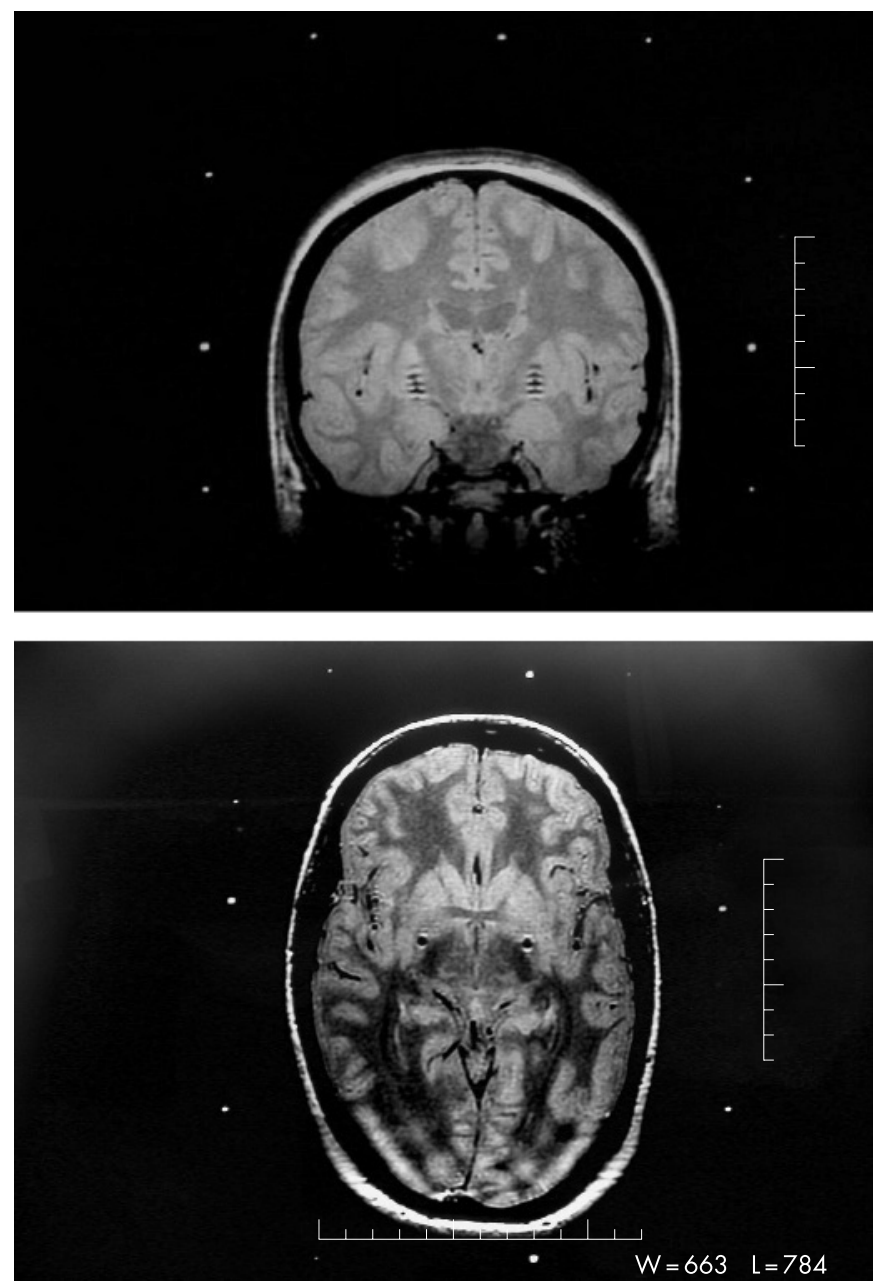

Figure 2 Immediate post-implantation coronal and axial MRI images of patient No 1 showing quadripolar 3387 electrodes located bilaterally in the globus pallidus internus.
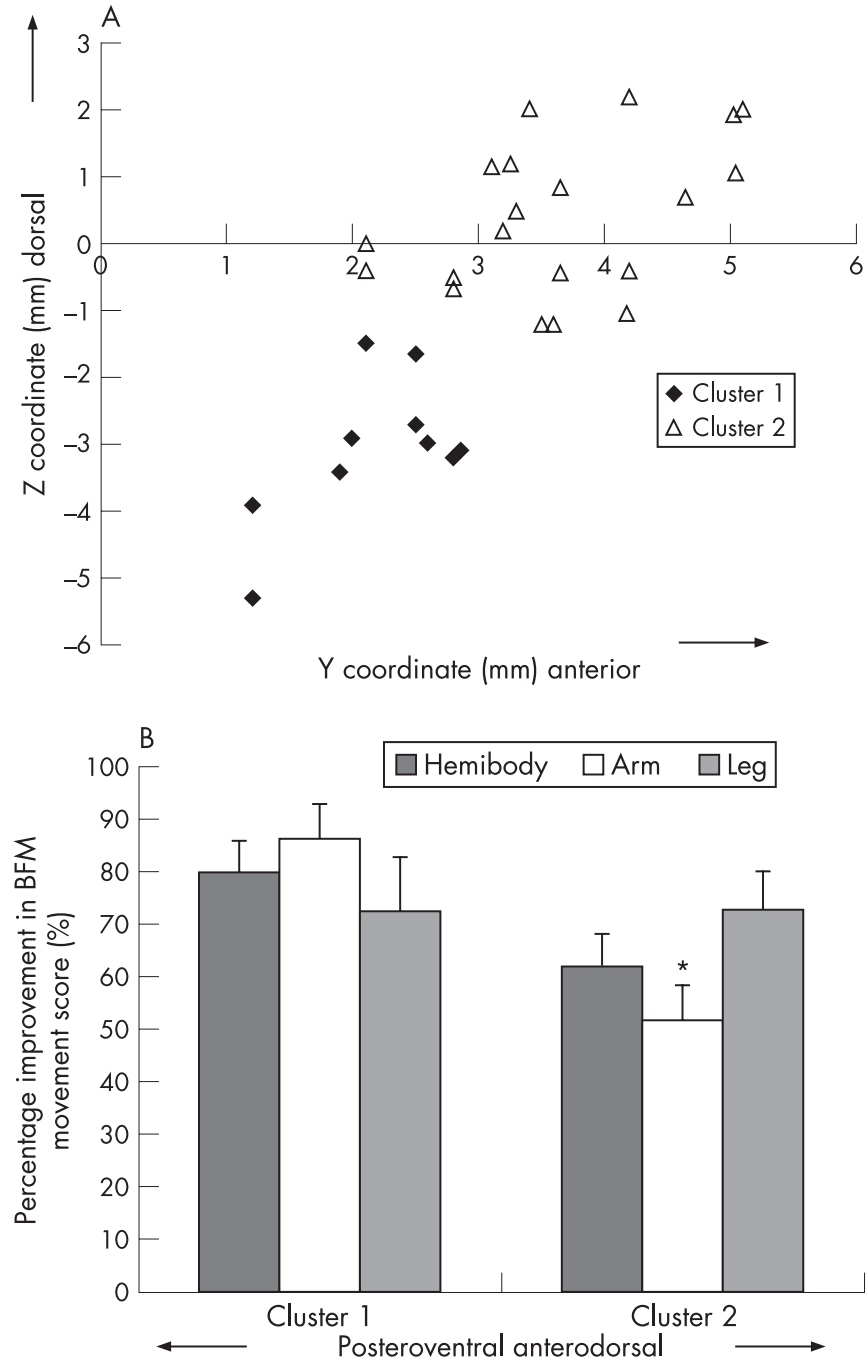

Figure 3 (A) Plot of $y$ and $z$ coordinate of the stimulated contact for 30 sides showing a linear distribution and the membership of spatial clusters. The origin of the plot is the mid point of the AC-PC line. Note cluster 1 is posteroventral and cluster 2 anterodorsal. (B) Mean percentage improvement in Burke-Fahn-Marsden (BFM) movement score for hemibody, arm and leg in clusters 1 and 2. For arm scores, improvement was significantly greater in cluster 1 than in $2\left({ }^{*} p=0.008\right)$. Values are mean (SEM). 

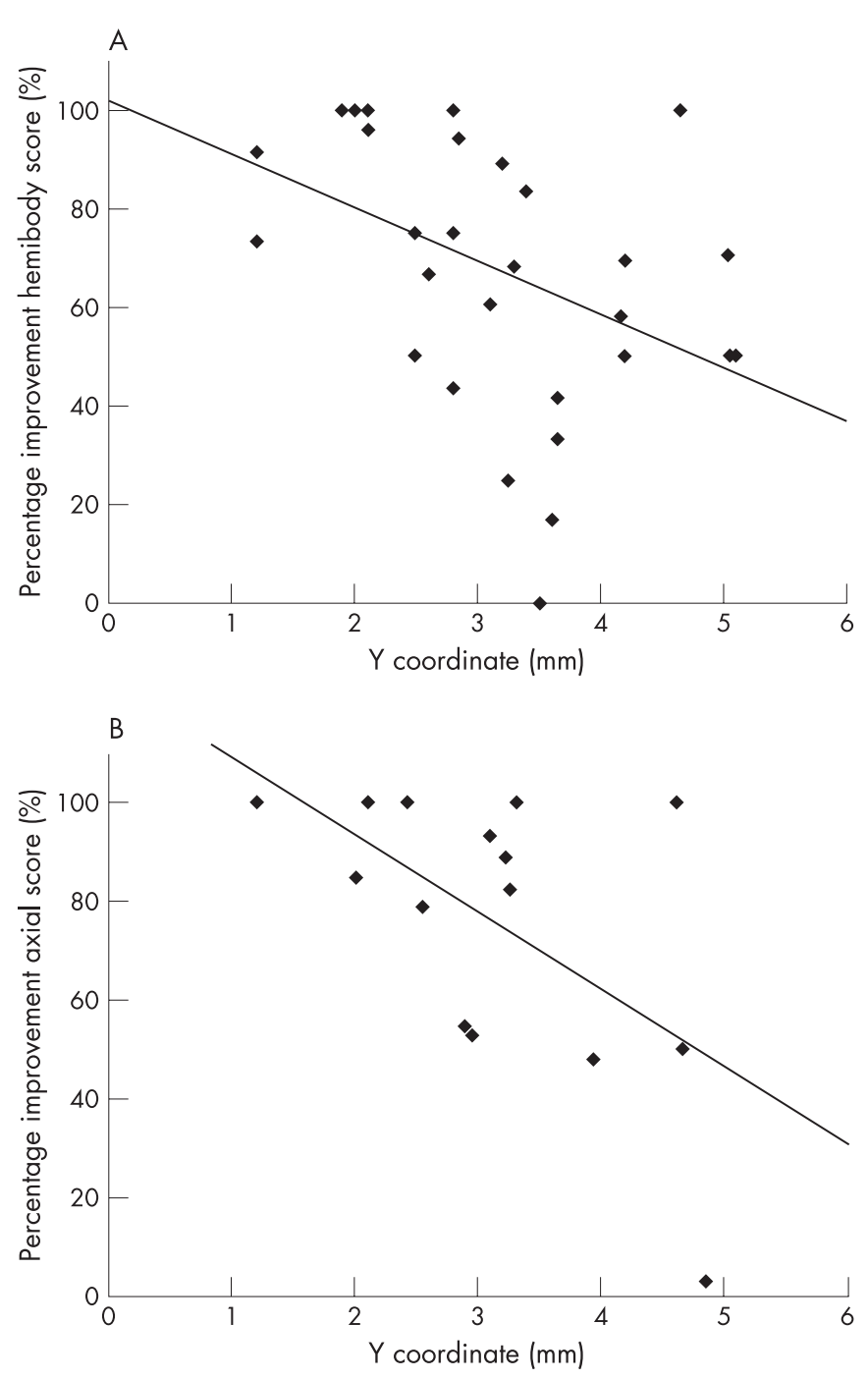

Figure 4 (A) Correlation between percentage change in hemibody BurkeFahn-Marsden (BFM) score and the $y$ coordinate of the stimulated contact in 30 sides $(r=-0.42, p=0.022)$. (B) Correlation between percentage change in axial BFM score and the average $y$ coordinate right and left sides in 15 patients $(r=-0.57, p=0.025)$.

enced by the $y \quad(F=22.4, p<0.0001)$ and $z \quad(F=64.8$, $\mathrm{p}<0.0001)$ coordinates but not by $\mathrm{x}(\mathrm{F}=0.02, \mathrm{p}=0.89)$, reflecting less variation in $\mathrm{x}$. Cluster $\mathrm{l}$ is the most posteroventral, cluster 2 is more anterodorsal. When plotted in the $\mathrm{y}-\mathrm{z}$ plane, the electrode contacts lie along a line reflecting the electrode trajectory and are significantly correlated $(r=0.748$, $\mathrm{p}<0.001$ ) (fig 3A).

\section{Effect of contact location on clinical outcome}

The mean percentage improvement in BFM movement scores for the contralateral hemibody, arm and leg for clusters 1 and 2 are shown in fig 3B. The improvement in hemibody score was greater in cluster 1 than in cluster $2(79.5 \%$ vs $61.9 \%)$ but this did not reach significance $(p=0.071)$. Analysis of arm and leg subscores revealed significantly greater improvement in cluster 1 than in cluster 2 for the arm $(86.3 \%$ vs $51.9 \%$; $=0.008)$ but not the leg (72.6\% vs 73\%; NS) (fig 3B). We were also interested in the number of sides with superior outcome defined as $>80 \%$ improvement in hemibody BFM score, a level of improvement used in a previous study of GPi DBS for dystonia using the BFM scale." Overall, there were 16 (of 30) sides with superior outcome, which occurred more frequently in cluster $1(8 / 10)$ than in cluster $2(8 / 20)\left(\chi^{2}=4.29, \mathrm{p}<0.05\right)$. The number of
DYTl sides did not differ significantly between clusters 1 (6/10) and $2(8 / 20)\left(\chi^{2}=1.07\right.$, NS). To further investigate if DYT1 status could account for the observed superior outcome for the arm in cluster 1, we performed repeated measures ANOVA on the arm subscores with the main factor of time (before and after surgery), between subjects factor of DYTl and covariates of $y$ and $z$ coordinates. The $x$ coordinate was omitted from the ANOVA because $\mathrm{x}$ did not contribute to electrode contact clustering. There was a significant main effect of time $(\mathrm{F}(1,26)=11.3 ; \mathrm{p}<0.005)$, time $\times y$ interaction $(\mathrm{F}(1,26)=4.6$; $\mathrm{p}<0.05)$ but no time $\times$ DYTl interaction $(\mathrm{F}(1,26)=0.29$; $\mathrm{p}=0.596)$. There was a significant inverse correlation between y coordinate and percentage improvement in hemibody BFM score $(\mathrm{r}=-0.42, \mathrm{p}=0.022)$, arm $(\mathrm{r}=-0.43, \mathrm{p}=0.019)$ but not leg $(\mathrm{r}=-0.14 ; \mathrm{NS})$. The same inverse correlation with $\mathrm{y}$ coordinate was observed for total axial scores $(r=-0.57$, $\mathrm{p}=0.025$ ) (fig 4).

We applied cluster analysis to the averaged $\mathrm{x}, \mathrm{y}$ and $\mathrm{z}$ coordinates in each patient which again identified two spatially distinct groups: a posteroventral cluster (four patients; centre $\mathrm{x}=20.7 \mathrm{~mm}, \mathrm{y}=2.05 \mathrm{~mm}, \mathrm{z}=-3.23 \mathrm{~mm}$ ) and more anterodorsal cluster ( 11 patients; centre $x=20.86 \mathrm{~mm}, y=3.55 \mathrm{~mm}$, $\mathrm{z}=0.14 \mathrm{~mm}$ ). The percentage improvement in axial BFM movement score was greater in the posteroventral than in the anterodorsal cluster (91\% vs $70.3 \%$ ), and for the trunk subscore this difference was significant (96\% vs $65 \%$; $\mathrm{p}<0.05$ ). Similarly, for the whole body BFM movement score, the percentage improvement was greater in the posteroventral than in the anterodorsal cluster $(88.7 \%$ vs $67.2 \% ; \mathrm{p}=0.02)$ and correlated with the y coordinate $(\mathrm{r}=-0.62, \mathrm{p}=0.013)$.

\section{DISCUSSION}

In the present study, our main finding is that superior improvement of dystonia is associated with chronic high frequency stimulation in the most posteroventral part of the GPi. The y (A-P) axis position of the electrode contact significantly influenced the efficacy of GPi DBS; the more posterior electrode contacts were therapeutically more effective.

The degree of improvement in patients with primary generalised dystonia following bilateral GPi DBS was similar to that previously reported. ${ }^{45}$ In contrast with these studies, we did observe a significantly better outcome in patients with DYTl. The superior outcome in DYTl could act as a confounding factor, but we consider this unlikely for the following reasons. Firstly, DYTl sides were not overrepresented in the posteroventral electrode contact cluster, and secondly, ANOVA showed no effect of DYTl status and a clear effect of $y$ coordinate on outcome. Our initial cluster analysis identified an anterodorsal-posteroventral gradient of electrode contact effectiveness, with better outcomes occurring more frequently in the posteroventral location. The subsequent finding of an exclusive correlation between the y coordinate and contralateral clinical outcome suggests y to be the more important predictor than $\mathrm{z}$ of electrode contact effectiveness.

The explanation for our findings may relate to pallidal anatomy. Anatomical and physiological studies in primates have shown that the sensorimotor territory of the GPi is ventral and posterior, ${ }^{10}{ }^{11}$ the somatotopic arrangement such that the face and arm are posterior and ventral, and the leg central and more dorsal. ${ }^{12}$ The pallidal anatomy supports our findings of superior efficacy of posteroventral stimulation as this is the sensorimotor area and modification of these circuits might be expected to alter the expression of dystonia. Pallidal somatotopy helps explain another aspect of our results; we found that posteroventral stimulation was best for the arm and overall, while for the leg, anterodorsal stimulation was of equivalent efficacy. These findings agree with GPi somatopy, in that the 
leg area extends more dorsally and centrally. Furthermore, our results agree with another study of GPi DBS contact location in PGD in which superior improvement for the leg was associated with electrode contact placement more centrally within the GPi, whereas posterior contact location was more efficient for the arm. ${ }^{9}$

Another relevant anatomical consideration is that the major routes of pallidal outflow, the ansa lenticularis and lenticular fasciculus, overlap in the posteroventral $\mathrm{GPi}^{13}$ making both routes of pallidal outflow accessible to intervention in this region. It should be mentioned that although our findings have concentrated on GPi which was the targeted and stimulated structure, a contributory role of the globus pallidus externus (GPe), which lies in intimate relation to GPi, cannot be excluded. Congruent with our targeting results, groups using microelectrode recording during pallidal DBS for dystonia identify an optimal target area in the posteroventrolateral GPi close to the border with GPe. ${ }^{14}$ At the very least, our data confirm the superiority of the posteroventral pallidal target, which includes GPi but may also additionally include a contributing effect from the adjacent GPe.

Clinical observations also provide support for the importance of the posteroventral pallidum as an area for modification of motor symptoms. Leksell observed that the beneficial effects of pallidotomy improved as the lesions were made in a more posterior location, ${ }^{15}$ which led to the successful reintroduction of posteroventral pallidotomy for PD. ${ }^{6}$ In patients with PD, stimulation in the posteroventral GPi alleviates rigidity and abolishes dyskinesia but may worsen akinesia, while stimulation of dorsal contacts improves akinesia, ${ }^{16}{ }^{17}$ suggesting functional segregation of effects. The volume of lesions in the posteroventral but not the anterodorsal part of the GPi correlates with the relief of dyskinesia in patients with PD. ${ }^{18}$ In addition, two of our patients developed akinesia with posteroventral stimulation, which resolved when more dorsal contacts were used. Taken together, these observations suggest that intervention in the posteroventral GPi is more "antikinetic" than in anterodorsal areas, and is consistent with our finding of optimal suppression of involuntary dystonic movements with stimulation in this region.

Our results raise an obvious and important question. Why did we not use the most ventral contacts in all patients? In most patients we did use the most ventral contacts; in some patients side effects limited their use and in one patient (patient No 7) more dorsal contacts were clinically superior to initial trials of more ventral contacts. However, in patient No 7, the stimulated contacts were $0.7 \mathrm{~mm}$ and $0.45 \mathrm{~mm}$ below AC-PC, therefore the good outcome in her case was still associated with more posteroventral rather than anterodorsal stimulation.

A limitation of our study is that it was not randomised or fully blinded, which may have introduced biases. Future studies randomising patients to either posteroventral or anterodorsal GPi stimulation with clinical assessment blinded to group would be an important next step to confirm our findings.

Our results confirm the superiority of the posteroventral GPi target for effective relief of dystonia with DBS. The accepted atlas target coordinates correspond well with the most effective contact location in our series. Our data would suggest that particular attention should be paid to targeting in the antero-posterior axis to ensure sufficiently posterior placement of the electrode. Based on our findings, we would advocate that in patients with GPi DBS for dystonia, the lowermost contacts of the quadripolar electrode, without side effects, be tried for chronic stimulation first, since these, with conventional orientation of electrode trajectory, will be the most posteroventral. The identification of an anterodorsal to posteroventral gradient of contact efficacy may be explained by the functional organisation and anatomy of GPi and its outflow tracts.

\section{ACKNOWLEDGEMENTS}

ST was supported by the Brain Research Trust UK and Medtronic; LZ received educational support from Medtronic UK; PL, KA and MH are supported by the Parkinson's Appeal UK.

\section{Authors' affiliations}

S Tisch, L Zrinzo, P Limousin, K Ashkan, M Hariz, Unit of Functional Neurosurgery, Sobell Department of Motor Neuroscience, Institute of Neurology, London, UK

K P Bhatia, N Quinn, Sobell Department of Motor Neuroscience, Institute of Neurology, London, UK

Competing interests: None.

\section{REFERENCES}

1 Fahn S, Bressman SB, Marsden CD. Classification of dystonia. Adv Neurol 1998;78:1-10.

2 Cooper IS, Hoen TI, Poloukhine N. Chemopallidectomy for dystonia musculorum deformans. J Am Geriatr Soc 1956;4:1208-13.

3 Coubes $\mathbf{P}$, Echenne B, Roubertie A, et al. Treatment of early-onset generalized dystonia by chronic bilateral stimulation of the internal globus pallidus. Apropos of a case. Neurochirurgie 1999;45:139-44.

4 Coubes $\mathbf{P}$, Cif $\mathrm{L}$, El Fertit $\mathrm{H}$, et al. Electrical stimulation of the globus pallidus internus in patients with primary generalized dystonia: long-term results. J Neurosurg 2004;101:189-94.

5 Vidailhet M, Vercueil L, Houeto JL, et al. French Stimulation du Pallidum Interne dans la Dystonie (SPIDY) Study Group. Bilateral deep-brain stimulation of the globus pallidus in primary generalized dystonia. N Engl J Med 2005;352:459-67.

6 Laitinen LV, Bergenheim AT, Hariz MI. Leksell's posteroventral pallidotomy in the treatment of Parkinson's disease. J Neurosurg 1992;76:53-61.

7 Hirabayashi H, Tengvar M, Hariz MI. Stereotactic imaging of the pallidal target. Mov Disord, 2002;17(Suppl.3), S130-4.

8 Burke RE, Fahn S, Marsden CD, et al. Validity and reliability of a rating scale for the primary torsion dystonias. Neurology 1985;35:73-7.

9 Vayssiere N, van der Gaag N, Cif L, et al. Deep brain stimulation for dystonia confirming a somatotopic organization in the globus pallidus internus. J Neurosurg 2004;101:181-8.

10 Parent A, Hazrati LN. Functional anatomy of the basal ganglia. I. The corticobasal ganglia-thalamo-cortical loop. Brain Res Brain Res Rev 1995;20:91-127.

11 lansek R, Porter R. The monkey globus pallidus: neuronal discharge properties in relation to movement. J Physiol 1980;301:439-55.

12 Delong MR, Crutcher MD, Georgopoulos AP. Primate globus pallidus and subthalamic nucleus: functional organization. J Neurophysiol 1985;53:530-43

13 Patil AA, Hahn F, Sierra-Rodriguez J, et al. Anatomical structures in the Leksell pallidotomy target. Stereotact Funct Neurosurg 1998;70:32-7.

14 Starr PA, Turner RS, Rau G, et al. Microelectrode-guided implantation of deep brain stimulators into the globus palllidus internus for dystonia: techniques, electrode locations and outcomes. Neurosurg Focus 2004;17:20-31.

15 Svennilson E, Torvik A, Lowe R, et al. Treatment of parkinsonism by stereotatic thermolesions in the pallidal region. A clinical evaluation of 81 cases. Acta Psychiatr Scand 1960;35:358-77.

16 Bejiani B, Damier P, Arnulf I, et al. Pallidal stimulation for Parkinson's disease. Two targets? Neurology 1997;49:1564-9.

17 Krack P, Pollak P, Limousin $P$, et al. Opposite motor effects of pallidal stimulation in Parkinson's disease. Ann Neurol 1998;43:180-92.

18 Kishore A, Panikar D, Balakrishnan S, et al. Evidence of functional somatotopy in GPi from results of pallidotomy. Brain 2000;123:2491-500. 